\title{
Multiplexed serotype-specific real time PCR assays - a valuable tool to support large scale surveillance for bluetongue virus infection.
}

\author{
Peter Kirkland ${ }^{1}$, B. Farrugia ${ }^{1}$, M.J. Frost ${ }^{1}$, C. Zhang $^{1}$, and Deborah Finlaison ${ }^{1}$ \\ ${ }^{1}$ Elizabeth Macarthur Agricultural Institute
}

February 7, 2022

\begin{abstract}
In the last decade, real time PCR has been increasingly adopted for bluetongue diagnosis with both broadly reactive and serotype-specific assays widely used. The use of these assays and nucleic acid sequencing technologies have enhanced bluetongue virus detection, resulting in the identification of a number of new serotypes. As a result, more than 30 different serotypes are proposed. Rapid identification of the virus serotype is essential for matching of antigens used in vaccines and to undertake surveillance and epidemiological studies to assist risk management. However, it is not uncommon for multiple serotypes to circulate in a region either concurrently or in successive years. It is therefore necessary to have a large suite of assays available to ensure that the full spectrum of viruses is detected. Nevertheless, covering a large range of virus serotypes is demanding from both a time and resource perspective. To overcome these challenges, real time PCR assays were optimised to match local virus strains and then combined in a panel of quadriplex assays, resulting in 3 assays to detect 12 serotypes directly from blood samples from cattle and sheep. These multiplex assays have been used extensively for bluetongue surveillance in both sentinel animals and opportunistically collected samples. A protocol to adapt these assays to capture variations in local strains of bluetongue virus and to expand the panel is described. Collectively these assays provide powerful tools for surveillance and the rapid identification of bluetongue virus serotypes directly from animal blood samples.
\end{abstract}

\section{Hosted file}

BTV type-specific assays - Final submitted.docx available at https://authorea.com/users/ 459253/articles/555580-multiplexed-serotype-specific-real-time-pcr-assays-a-valuabletool-to-support-large-scale-surveillance-for-bluetongue-virus-infection 